$$
\begin{array}{r|l}
\text { Jurnal Sains Komputer dan Teknologi Informasi } & \text { Page } \\
\text { e-issn: 2655-7460. Volume 2 No.1, November 2019 } & 16-23
\end{array}
$$

\title{
APLIKASI CUCI MOBIL ABC BERBASIS WEB MOBILE
}

\author{
Mochammad Ichsan \\ Sekolah Tinggi Manajemen Informatika dan Komputer (STMIK) \\ Palangka Raya \\ Jl. G.Obos No.114, Palangka Raya 73112 Indonesia \\ E-mail: salafi_ichsan@yahoo.com
}

\begin{abstract}
ABSTRAK
Mengantri merupakan salah satu fenomena yang sering terjadi dalam kehidupan sehari-hari dan sering ditemui dalam fasilitas pelayanan umum. Antrian akan terjadi bila banyak pelanggan yang dilayani melebihi kapasitas layanan yang tersedia. Antrian sering dijumpai di fasilitas-fasilitas umum seperti tempat pengisian bahan bakar, supermarket, bank, anjungan tunai mandiri dan fasilitas umum lainnya tidak terkecuali tempat pencucian mobil. Meningkatnya jumlah kendaraan roda dua dan roda empat menyebabkan meningkatnya permintaan jasa pencucian mobil atau motor. Hal ini tentu saja mempengaruhi persaingan bisnis dalam bisnis ini salah satunya tentu saja dengan meningkatkan layanan pelanggan dalan hal antrian sehingga pelanggan tidak terlalu menunggu lama atau setidaknya ada kemudahan dalam proses mencuci mobilnya dimana antrian dapat diakses melalui smartphone. Metode - metode penulisan yang digunakan dalam penelitian ini meliputi metode pengumpulan data (metode kepustakaan, metode dokumentasi, dan metode eksperimen) dan metode pengembangan sistem. Pada penelitian ini telah berhasil diimplementasikan sebuah aplikasi cuci mobil ABC berbasis web mobile dengan menggunakan bahasa pemrograman $p h p$ dan database yang digunakan berbasis Struktured Query Language (SQL) yaitu MySQL dengan nama carwash.sql dengan 5 (lima) buah tabel. penulis menerapkan metode pengembangan perangkat lunak waterfall.
\end{abstract}

Kata kunci : Aplikasi, Cuci Mobil, Web Mobile.

\section{PENDAHULUAN}

Antrian sering dijumpai di fasilitas-fasilitas umum seperti tempat pengisian bahan bakar, supermarket, bank, anjungan tunai mandiri dan fasilitas umum lainnya tidak terkecuali di instansi pemerintah atau swasta. Meningkatnya jumlah kendaraan roda dua dan roda empat menyebabkan meningkatnya permintaan jasa pencucian mobil atau motor. Hal ini tentu saja mempengaruhi persaingan bisnis dalam bisnis ini salah satunya tentu saja dengan meningkatkan layanan pelanggan dalan hal antrian sehingga pelanggan tidak terlalu menunggu lama atau setidaknya ada kemudahan dalam proses mencuci mobilnya. Keadaan ini juga menyebabkan banyaknya masyarakat yang mengeluh karena harus menunggu antrian terlalu lama yang berdampak terganggunya aktifitas kerja rutin masyarakat karena harus menunggu antrian layanan. Dengan latar belakang yang telah dipaparkan pada paragraf sebelumnya, penulis tertarik untuk membuat sebuah "Aplikasi Cuci Mobil ABC Berbasis Web Mobile ".

Metodologi yang digunakan dalam pembuatan aplikasi ini adalah waterfall. Tools yang digunakan adalah Adobe Dreamwever CS6 dengan bahasa pemrograman PHP dan XAMPP dengan bahasa MySQL sebagai database. Metode yang digunakan dalam pengumpulan data seperti observasi, dokumentasi dan kepustakaan.

\section{KAJIAN TEORI \\ 2.1 Aplikasi}

Menurut Abdurahman dan Asep (2014), aplikasi adalah program siap pakai yang dapat digunakan untuk menjalankan perintah-perintah dari pengguna aplikasi tersebut dengan tujuan mendapatkan hasil yang lebih akurat sesuai dengan tujuan pembuatan aplikasi tersebut.

\subsection{Antri}

Menurut Gross dan Haris dalam Fadlilah (2017), antri atau antrian dapat digambarkan sebagai kedatangan pelanggan untuk memperoleh pelayanan, menunggu untuk pelayanan jika pelayanan tersebut tidak cepat, dan jika telah menunggu untuk mendapatkan pelayanan, kemudian meninggalkan sistem setelah pelanggan dilayani.

\subsection{Web Mobile}

Menurut Abdurahman (2016), Web Mobile adalah lanjutan dari aplikasi web tradisional. Saat 
online menggunakan smartphone, tablet, atau komputer, desainnya beradaptasi dengan perangkat yang digunakan tersebut. Desain yang fleksibel ini memaksimalkan kemampuan web browser yang digunakan di perangkat mobile yang digunakan.

Lebih jelasnya, web mobile merupakan halaman-halaman yang berisi informasi yang ditampilkan oleh browser seperti Mozilla Firefox, Google Chrome atau yang lainnya, tapi memiliki tampilan yang dapat menyesuaikan dengan perangkat pengaksesnya.

\section{METODE}

Adapun metode yang digunakan dalam penelitian ini adalah dengan menggunakan System Development Life Cycle (SDLC). Pengembangan perangkat lunak (software) menggunakan model pengembangan perangkat lunak Waterfall. Fasefase yang dilakukan penulis dengan metode ini adalah:

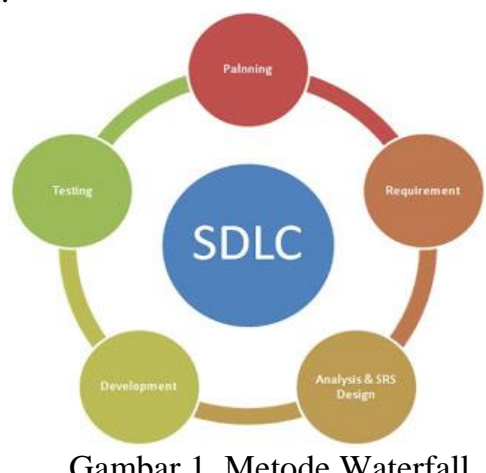

Gambar 1. Metode Waterfall

(Sumber : Bassil, 2012)

\section{PERANCANGAN SISTEM}

Adapun teknik analisa yang digunakan penulis dalam menyelesaikan penelitian ini adalah dengan menggunakan System Development Life Cycle (SDLC). Pengembangan perangkat lunak (software) menggunakan model pengembangan perangkat lunak Waterfall. Fase-fase yang dilakukan penulis dengan metode ini adalah:

\subsection{Perencanaan (Planning)}

Tahapan untuk menentukan informasi apa yang dibutuhkan oleh sistem atau menentukan kebutuhan dari sistem yang akan dibuat. Dalam proses perencanaan penulis mengumpulkan data seputar layanan cuci mobil, seperti jenis layanan, harga serta proses transaksi.

\subsection{Analisis Sistem (Analysis System)}

Tahapan ini mengumpulkan kebutuhan secara lengkap kemudian dianalisis dan didefinisikan kebutuhan yang harus dipenuhi oleh aplikasi yang akan dibangun. Pada tahap ini penulis menganalisa semua data yang diperoleh pada tahap perencanaan baik itu form dari data layanan, tampilan sistem, bentuk laporan informasi apa yang akan disajikan, kebutuhan sistem baik perangkat keras dan perangkat lunak yang akan digunakan pada tahap desain, implementasi, dan pengujian.

\subsection{Desain (Design)}

Tahapan perancangan sistem baru berdasarkan data-data yang telah dikumpulkan pada tahap sebelumnya dengan cara merancang perangkat lunak dengan Unified Modeling Language (UML), Entity Relationship Diagram (ERD), dan Interface Design yang telah direncanakan dan dianalisa.

\subsubsection{Use Case Diagram}

Use case diagram dapat dilihat pada Gambar 2.

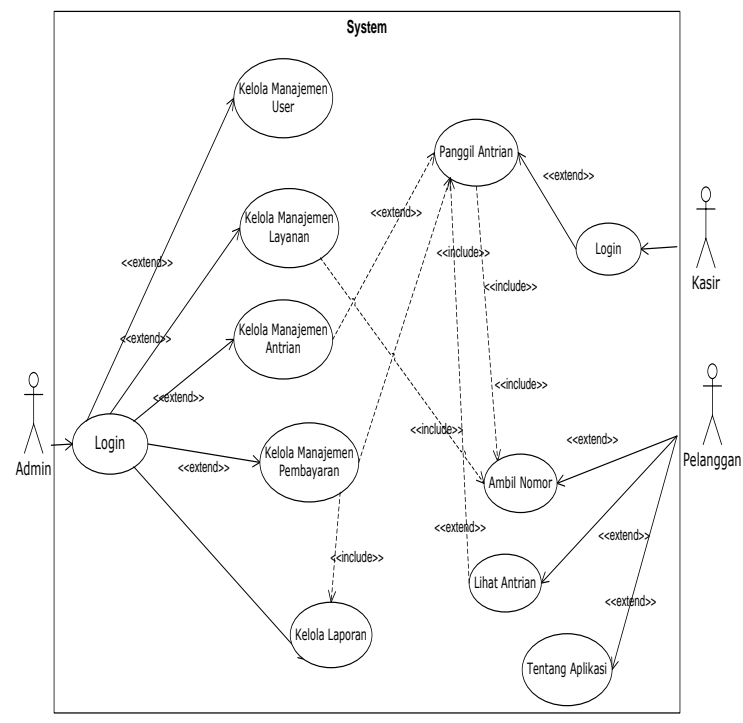

Gambar 2. Use Case Diagram

Use case diagram menggambarkan terdapat 3 actor admin, kasir dan pelanggan dimana use case ini merupakan suatu desain proses dari aplikasi.

Proses kerja sistem tergantung keinginan actor dalam arti bahwa setiap menu yang ada didalam sistem dapat dikelola keseluruhan atau dapat memilih menu yang akan dibuka atau digunakan (extend), jika menu telah dibuka maka terhubung terhadap pengelolaan data lain secara fungsional dalam arti bahwa pengelolaan suatu data akan berpengaruh dengan data lain (include). 


$$
\begin{array}{r|l}
\text { Jurnal Sains Komputer dan Teknologi Informasi } & \text { Page } \\
\text { e-issn: 2655-7460. Volume 2 No.1, November 2019 } & 16-23
\end{array}
$$

Tugas dari masing-masing aktor tersebut adalah sebagai berikut:

1) Admin

Peran admin pada aplikasi bertugas mengelola seluruh data yang ada pada database seperti data admin, jenis layanan, antrian, pembayaran, dan laporan pengelolaan data meliputi tambah data, ubah data dan hapus data. Sebelum mengelola data admin harus masuk ke halaman admin dengan terlebih dahulu login dengan memasukkan username dan password.

2) Kasir

Peran admin pada aplikasi bertugas memanggila antrian. Sebelum melakukan proses pemanggilan antrian, kasir harus masuk ke halaman kasir dengan terlebih dahulu login dengan memasukkan username dan password.

3) Pelanggan

Peran pelanggan pada aplikasi dapat melakukan proses mendaftar antrian, melihat informasi layanan, kontak, dan melihat antrian yang berjalan.

\subsubsection{Entity Relation Diagram (ERD)}

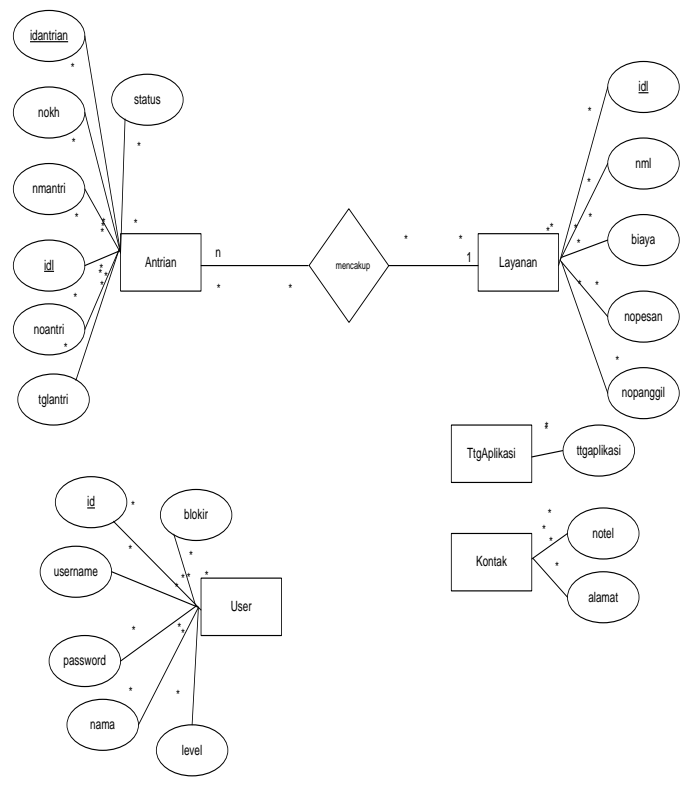

Gambar 3. Entity Relation Diagram (ERD)

Dari Gambar 3 dapat dijelaskan ada dua entitas yang saling berelasi one to many yaitu entitas layanan dengan antrian karena satu layanan digunakan lebih dari sekali. Sedangkan entitas kontak, ttgaplikasi dan entitas user tidak berelasi.

\subsubsection{Rancangan Tampilan Program}

1. Halaman Pengunjung

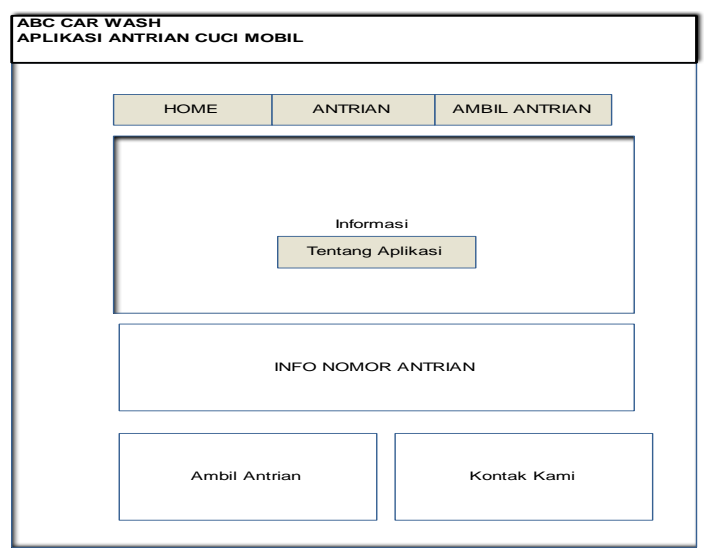

Gambar 4. Rancangan Tampilan Halaman Utama Pengunjung

Pada halaman pengunjung terdapat menu yang terdiri dari :

a) Tentang Aplikasi adalah halaman utama sekaligus informasi tentang aplikasi.

b) Antrian adalah info nomor antrian yang sedang berjalan.

c) Ambil Nomor Antrian adalah halaman untuk melakukan mengisi data pelanggan dan mengambil nomor antrian.

d) Kontak adalah nomor telepon atau HP yang bisa dihubungi.

2. Halaman Admin

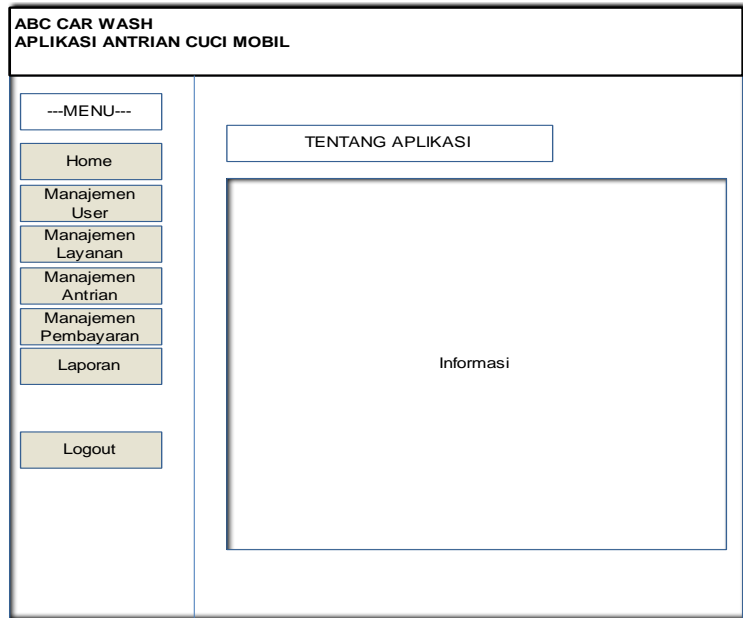

Gambar 5. Rancangan Tampilan Halaman Utama Admin

Pada halaman admin terdapat menu yang terdiri dari :

a) Manajemen User adalah halaman yang digunakan admin untuk mengelola data pengguna aplikasi atau administrator. 
b) Manajemen Layanan adalah halaman yang digunakan admin untuk mengelola data jasa layanan cuci.

c) Manajemen Antrian adalah halaman yang digunakan admin untuk mengelola dan melihat antrian.

d) Manajemen Pembayaran adalah halaman yang digunakan admin untuk mengelola pembayaran pelanggan berdasarkan jasa layanan dan cetak nota.

e) Laporan adalah laporan pendapatan dan transaksi.

f) Logout adalah menu keluar dari halaman admin atau kasir.

\subsection{Implementasi (Coding)}

Tahapan dalam ini program akan diterjemahkan ke dalam kode-kode (coding) dengan menggunakan bahasa pemrograman yang sudah ditentukan yaitu PHP dan MySQL dengan model MVC (Model, View, Controller), sehingga aplikasi dapat terwujud sesuai dengan perencanaan dan desain yang dibuat.

\subsection{Pengujian (Testing)}

Tahapan kegiatan untuk melakukan pengetesan program yang sudah dibuat, apakah sudah sesuai atau belum yang akan diuji dengan cara manual. Jika testing sudah benar maka program boleh dipergunakan. Pada tahap ini penulis melakukan pengujian black box untuk melihat sejauh mana kesuksesan atau keberhasilan serta kesesuaian dengan perencanaan dan desain yang dibuat pada tahap sebelumnya.

\section{HASIL DAN PEMBAHASAN \\ 5.1 Halaman Pelanggan}

a. Halaman Menu Utama Antrian Pelanggan

Untuk halaman utama antrian pelanggan untuk mengakses atau melihat antrian dapat dilihat pada Gambar 6.

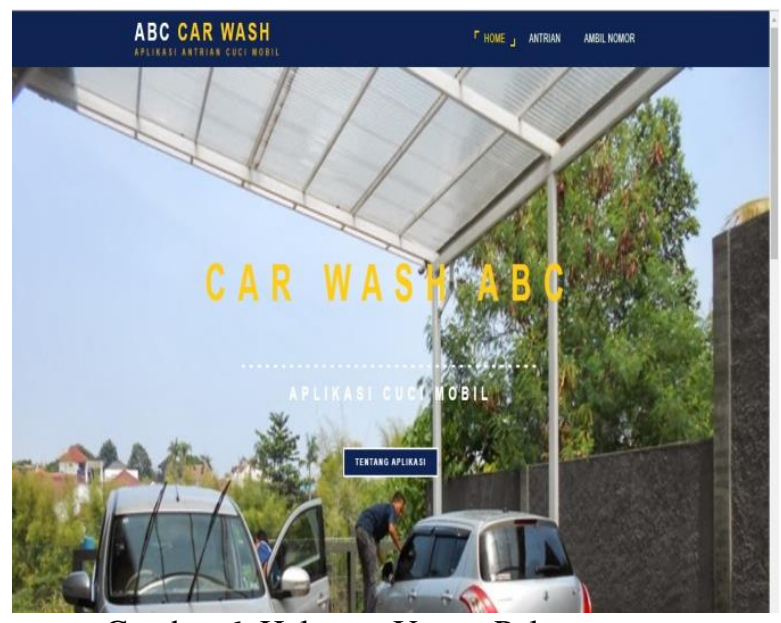

Gambar 6. Halaman Utama Pelanggan

Pada halaman utama, pelanggan dapat mengakes atau melihat antian yang sedang berjalan seperti terlihat pada Gambar 7.

\section{ANTRIAN LAYANAN}

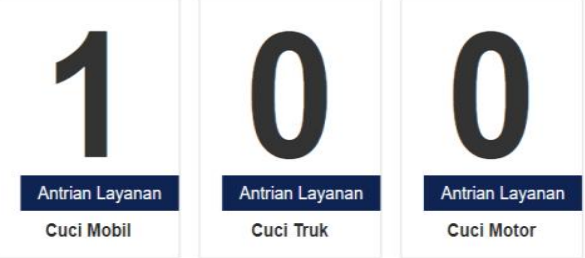

Gambar 7. Halaman Nomor Antrian

Pelanggan mengambil nomor antrian pelanggan dengan mengisi biodata (nama dan nomor polisi), kemudian memilih jenis layanan lalu akan mendapatkan nomor antrian sesuai dengan jenis layanan yang dipilih, seperti terlihat pada Gambar 8.

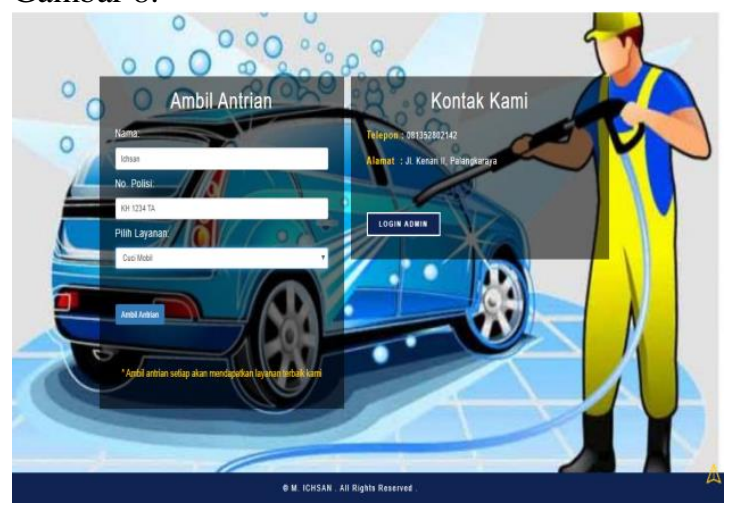




\section{Jurnal Sains Komputer dan Teknologi Informasi Page e-issn: 2655-7460. Volume 2 No.1, November 2019 16-23}

\begin{tabular}{|c|c|c|}
\hline \multicolumn{3}{|c|}{ :: $\underset{\text { JL. KENARI II, PALANGKARAYA }}{\mathbf{A B C} \text { CAR WASH }}$} \\
\hline Nama & : Haris & No. Antri : \\
\hline No. Polisi & : $\quad$ DA $2233 \mathrm{Z}$ & \\
\hline Tanggal & : 2019-12-03 & \\
\hline Layanan & : Cuci Motor & \\
\hline
\end{tabular}

Gambar 8. Nomor Antrian

Pada halaman pengujung juga terdapat halaman tentang aplikasi yang berisi informasi tentang aplikasi. Seperti terlihat pada Gambar 9.

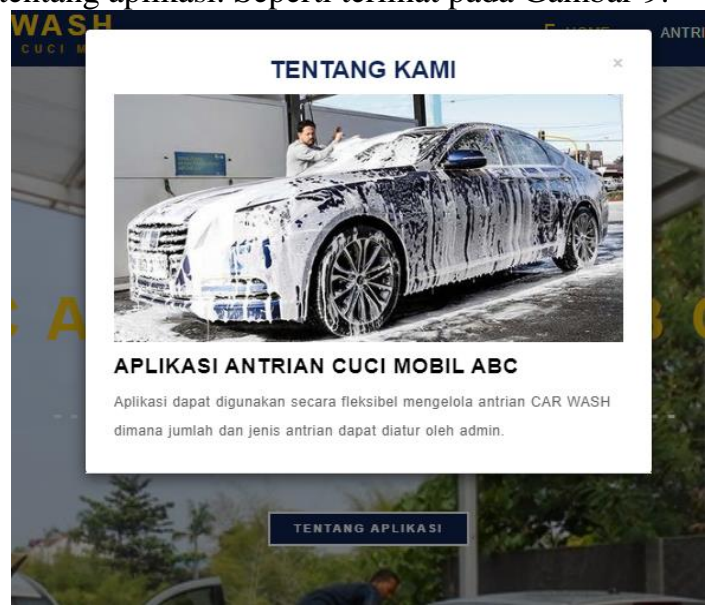

Gambar 9. Halaman Tentang Aplikasi

\subsection{Halaman Admin}

a. Login

Untuk masuk ke halaman admin, harus mengisi username dan password pada halaman utama login seperti terlihat pada Gambar 10.

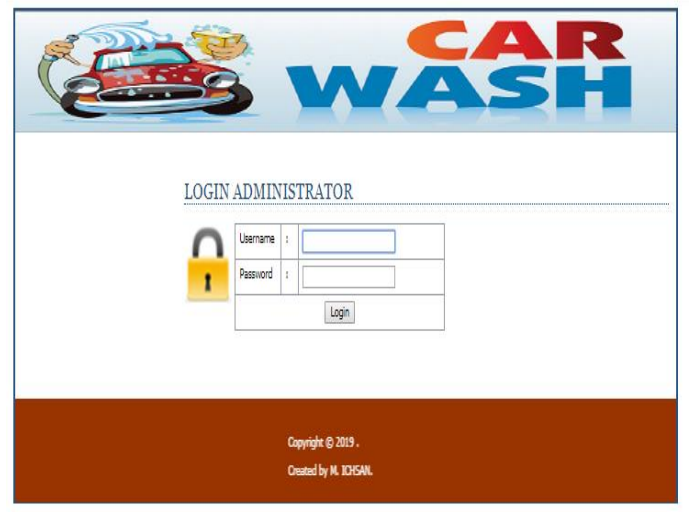

Gambar 10. Tampilan Login Admin

Halaman ini juga digunakan untuk masuk ke halaman kasir username dan password menentukan user masuk sebagai admin atau kasir yang hak aksesnya ditentukan pada saat menambahkan user pada menu manajemen user.

b. Menu Utama Admin
Setelah login berhasil, maka tampil halaman menu utama admin seperti terlihat pada Gambar 11.

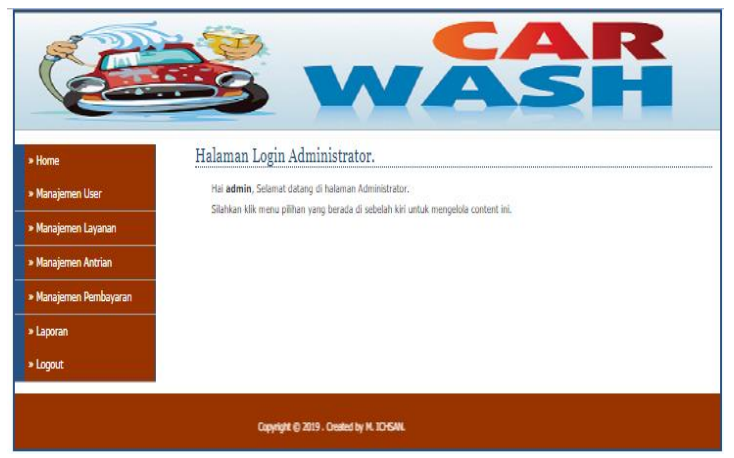

Gambar 11. Menu Utama Admin

Pada halaman utama admin terdapat menu home untuk mengakses halaman utama, manajemen user untuk mengelola data user yang terdiri dari admin dan kasir, manajemen layanan untuk mengelola jumlah layanan yang tersedia, manajemen pembayaran yang digunakan untuk mengelola pembayaran pelanggan, Manajemen antrian untuk menentukan jumlah antrian dan mereset antrian jika diperlukan saat perubahan hari atau tanggal, laporan transaksi serta logout untuk keluar dari halaman admin.

c. Manajemen User

Pada manajemen user terdapat fasilitas untuk menambah data user seperti terlihat pada Gambar 12 .

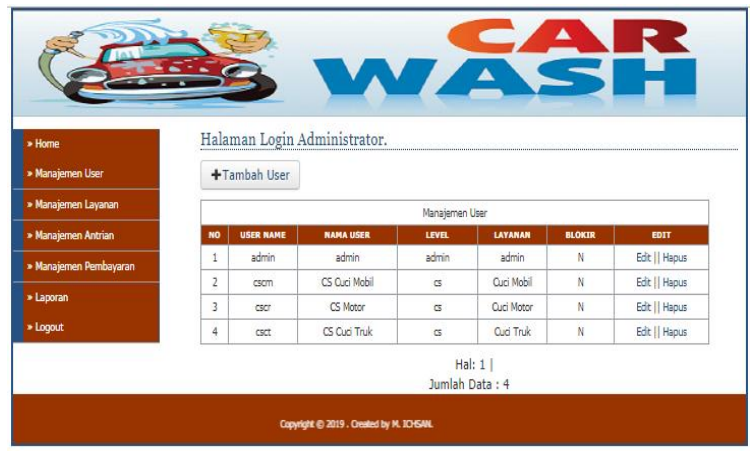

Gambar 12. Halaman Manajemen User

Pada halaman manajemen user terdapat fasilitas untuk mengelola data user, proses tersebut meliputi tambah data user, edit data user yang telah ada, dan hapus data user serta menentukan apakah user memiliki hak akses sebagai admin atau kasir, pada halaman ini juga admin dapat memblokir hak akses user jika diperlukan.

d. Manajemen Layanan

Selanjutnya adalah halaman manajemen layanan seperti terlihat pada Gambar 13. 


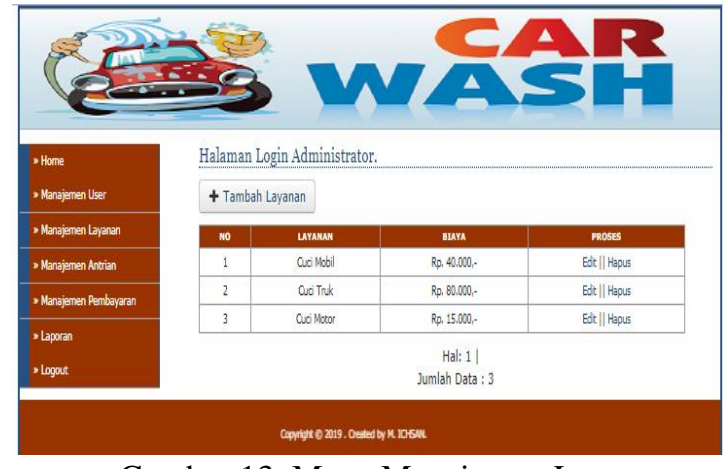

Gambar 13. Menu Manajemen Layanan

Pada halaman manajemen layanan terdapat fasilitas untuk mengelola data lokat, proses tersebut meliputi tambah data, edit data yang telah ada, dan hapus data layanan.

e. Manajemen Antrian

Berikutnya adalah menu manajemen antrian seperti terlihat pada Gambar 14.

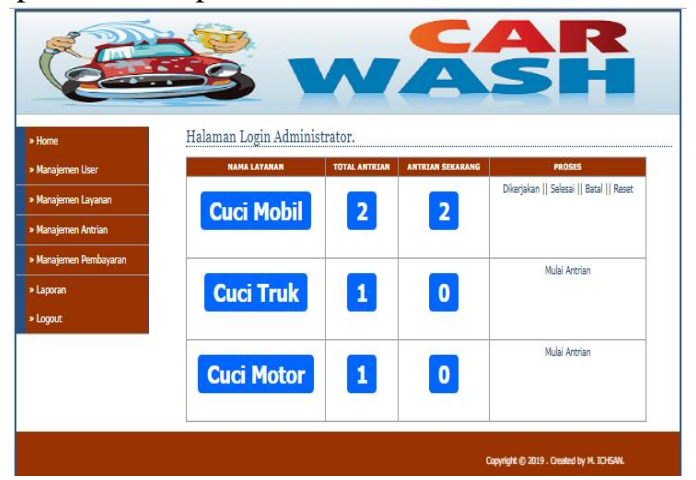

Gambar 14. Halaman Manajemen Antrian

Pada halaman ini terdapat fasilitas untuk mengelola antrian baik dan status layanan (dikerjakan/selesai/batal/next/reset).

f. Manajemen Pembayaran

Menu dibawahnya setelah manajemen antrian adalah menu manajemen pembayaran seperti terlihat pada Gambar 15.

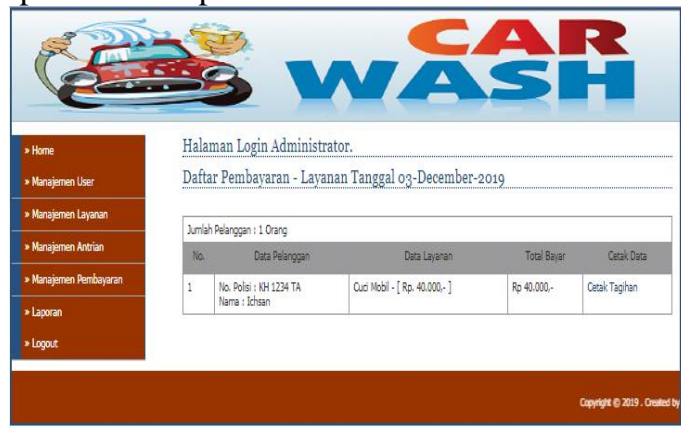

Gambar 15. Halaman Manajemen Pembayaran
Pada halaman ini terdapat fasilitas untuk mengelola pembayaran yang akan ditampilkan pada halaman pembayaran dimana admin dapat mencetak nota pembayaran seperti terlihat pada Gambar 16.

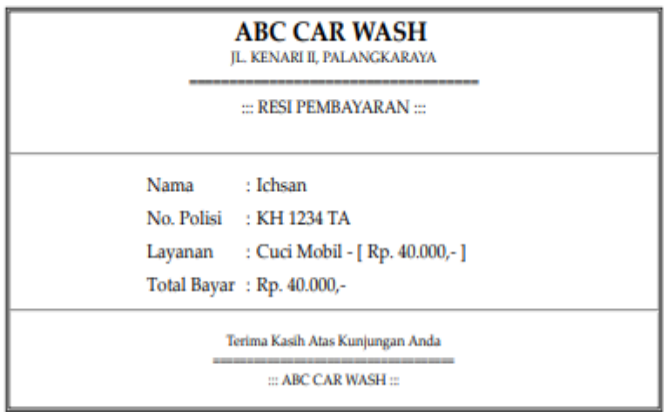

Gambar 16. Cetak Pembayaran

g. Menu Laporan

Menu dibawahnya setelah manajemen pembayaran adalah menu laporan seperti terlihat pada Gambar 17.

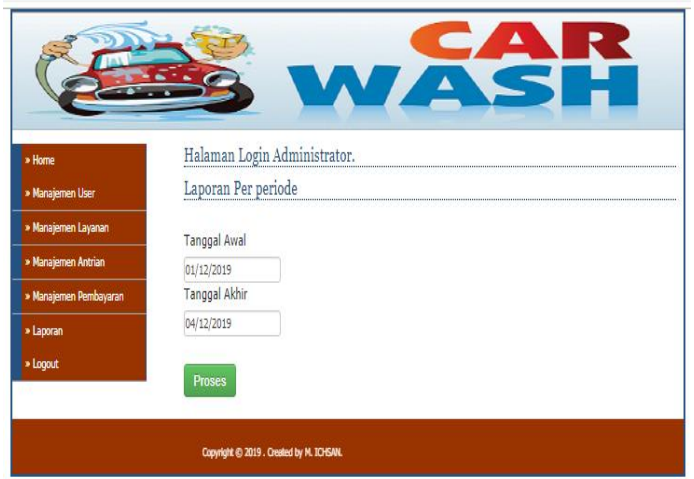

Gambar 17. Tampilan Halaman Laporan

Pada halaman ini terdapat fasilitas untuk mengelola laporan berdasarkan periode tanggal tertentu yang dapat diatur admin. Adapun bentuk laporan yang dapat dicetak terlihat pada Gambar 18 .

\begin{tabular}{|c|c|c|c|}
\hline \multicolumn{4}{|c|}{ ABC CAR WASH } \\
\hline \multicolumn{4}{|c|}{ :: Laporan Periode ::: } \\
\hline \multicolumn{4}{|c|}{ Per 01-December-2019 sampai 04-December-2019 } \\
\hline \multicolumn{4}{|c|}{ Jumlah felangsen: 10rang } \\
\hline Na. & Data Planggan & Data Layanan & Total Byyz \\
\hline & $\begin{array}{l}\text { Na. Polisis: KH 124 TA } \\
\text { Nama :lchsun } \\
\end{array}$ & 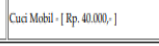 & Rp 40.000, \\
\hline \multicolumn{4}{|c|}{ Total Pendapatan $\operatorname{Rp~40.000,-}$} \\
\hline
\end{tabular}

Gambar 18. Cetak Laporan Perperiode 


\section{Jurnal Sains Komputer dan Teknologi Informasi Page \\ e-issn: 2655-7460. Volume 2 No.1, November 2019 16-23}

\subsection{Halaman Kasir}

a. Login Kasir

Untuk masuk ke halaman kasir, harus mengisi username dan password pada halaman utama login seperti terlihat pada Gambar 19.

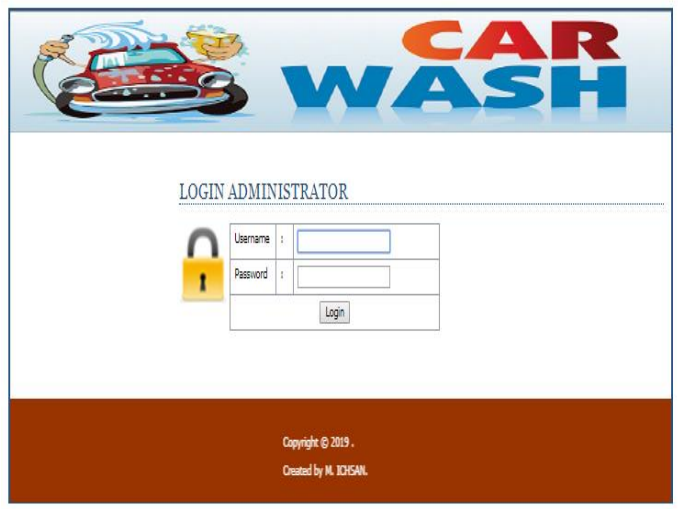

Gambar 19. Tampilan Login Kasir

Halaman ini sama dengan yang digunakan admin untuk masuk ke halaman admin. Untuk masuk ke halaman kasir username dan password menentukan user masuk sebagai admin atau kasir yang hak aksesnya ditentukan pada saat menambahkan user pada halaman kasir.

b. Menu Utama Kasir

Setelah login berhasil, maka tampil halaman menu utama kasir seperti terlihat pada Gambar 20.

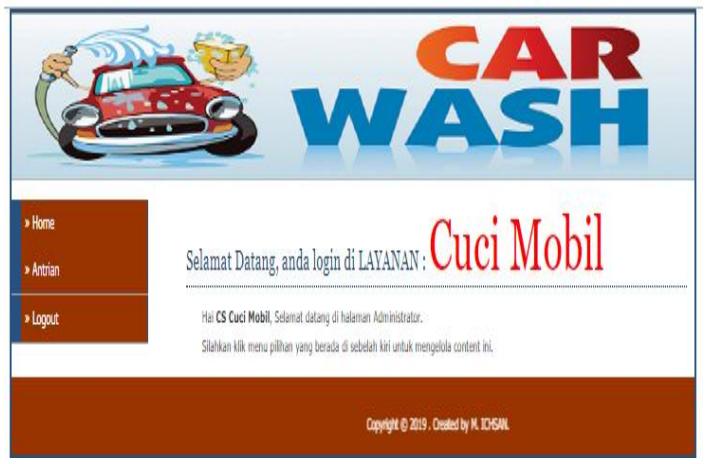

Gambar 20. Tampilan Menu Utama Kasir

Pada halaman utama kasir hanya terdapat menu home untuk mengakses halaman utama, antrian untuk memanggil pelanggan berdasarkan nomor antrian, serta logout untuk keluar dari halaman kasir.

c. Menu Antrian

Selanjutnya adalah menu antrian seperti terlihat pada Gambar 21.

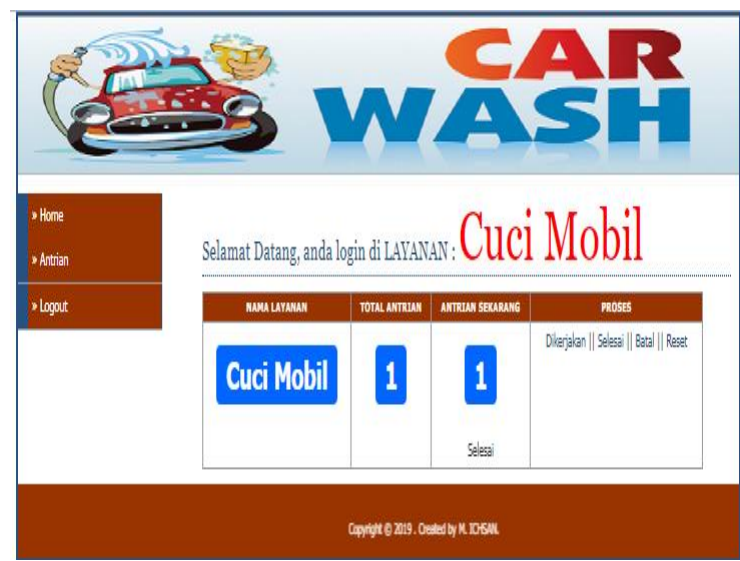

Gambar 21. Tampilan Halaman Menu Antrian

Pada halaman menu antrian, aktifitas yang dapat dilakukan kasir terdiri dari:

1) Memanggil antrian selanjutnya dengan memilih tombol NEXT dan dapat mengetahui jumlah pelanggan yang antri.

2) Menekan tombol dikerjakan digunakan untuk memberikan status layanan dikerjakan untuk memudahkan memantau antrian.

3) Menekan tombol selesai digunakan untuk memberikan status layanan telah selesai dikerjakan dan dapat mencetak nota pembayaran yang dilakukan pada menu manajemen pembayaran.

4) Menekan tombol batal digunakan untuk memberikan status layanan batal jika pelanggan tidak datang.

5) Menekan tombol reset digunakan untuk mengatur antrian kembali ke angka nol biasanya digunakan saat pergantian hari untuk memulai antrian.

d. Logout

Menu terakhir adalah logout, proses ini digunakan untuk keluar dari halaman admin atau kasir.

\section{KESIMPULAN DAN SARAN 6.1 Kesimpulan}

Dalam mengimplementasikan Aplikasi Cuci Mobil ABC Berbasis Web Mobile maka dapat disimpulkan bahwa pembangunan aplikasi menggunakan metode menggunakan SDLC (System Development Life Cycle) yaitu proses logis yang digunakan oleh analis sistem untuk menggambarkan sebuah sistem informasi. Metode SDLC menggunakan pendekatan sistem air terjun (Waterfall). Tahapan Analisis Sistem dalam tahap ini yang akan dilakukan penulis adalah merancang pemodelan system dan desain interface program 
agar alur dari proses program tersebut jelas. Untuk pemodelan sistem penulis menggunakan pemodelan sistem Unified Modelling Language (UML) dan ERD.

\subsection{Saran}

a. Penulis mengharapkan untuk pengembangan aplikasi selanjutnya, diharapkan juga dapat dijalankan diberbagai platform, seperti Blackberry $O S, I O S$, dan lain sebagainya, sehingga dapat menjangkau semua sistem operasi smartphone yang digunakan oleh user.

b. Sistem ini hendaknya dapat dipergunakan oleh user yang memahami sistem komputerisasi, sehingga proses pengelolaan datanya dapat dilakukan dengan baik.

c. Penambahan fitur selain antrian seperti data keuangan dan data pegawai.

\section{DAFTAR PUSTAKA}

Abdurahman, H., dan Asep R. R., 2014. "Aplikasi Pinjaman Pembayaran Secara Kredit pada Bank Yudha Bkati” Jurnal Computech \& Bisnis, Vol. 8, No. 2.

Abdurahman, M. 2016. "Sistem Informasi Jadwal Perkuliahan Berbasis Web Mobile pada Politeknik Sains dan Teknologi Wiratama Maluku Utara". Indonesian Journal on Networking and Security - Volume 5 No 2 Mei 2016.

Bassil, Y., 2012. "A Simulation Model For the Waterfall Software Development Life Cycle". Int. J. Eng. Tecnol Computech \& Bisnis, Vol. 2, No. 5, pp.2049-3444.

Fadlillah, M., P., N. 2017. "Sistem Antrian pada Pelayanan Customer Servis PT. Bank X". Jurnal Gaussian, Volume 6, Nomor 1, Tahun 2017, Halaman 71-80.

Ganevi dan Wardati. 2013. "Pembuatan Sistem Antrian Pelayanan Masyarakat pada Dinas Kependudukan dan Pencatatan Sipil Kabupaten Pacitan". Indonesian Jurnal on Computer Science Speed (IJCSS) 19 FTI UNSA Vol 11 No 2 - Mei 2013 ijcss.unsa.ac.id.

Ichsan, M., Qamaruzzaman, M, H., Rahmadianur, M, A., 2019. "Rancang Bangun Permainan Misi Panglima Batur Menggunakan Engine Scirra Construct 2". Jurnal Sains Komputer dan Teknologi Informasi. Vol 1 Issue 2 eISSN 2655-7460. https://doi.org/10.33084/jsakti.v1i2.870.

Kimmel, P. 2015. “UML Demystified”. McGrawHill Education. Los Angeles.
Mayangsari, Y., dan Pratiwi. 2016. "Sistem Antrian Teller Bank Mandiri Sebagai Upaya Meningkatkan Efiensi Kecepatan Transaksi”. Indonesian Jurnal Ekonomi \& Bisnis, Hal 49-60 Vol 1 No 1.

Sam'ani. Annisa, S., Heri., 2018. "Rancang Bangun Aplikasi Pengawasan Dan Pengendalian Komputer Laboratorium Multimedia STMIK Palangkaraya”. Jurnal Sains Komputer dan Teknologi Informasi. Vol 1 Issue 1 e-ISSN 2655-7460. https://doi.org/10.33084/jsakti.v1i1.548 